\title{
Revisão
}

\section{O Orçamento Participativo na Gestão Pública}

\author{
Sony Lins Jesus dos Santos ${ }^{1}$; Jorge Keven Vilas Boas ${ }^{2}$; Mário Lopes de Oliveira ${ }^{3}$; \\ Mayara Lima da Silva ${ }^{4}$; Hesler Piedade Caffé Filho
}

\begin{abstract}
Resumo: A Constituição Federal estabelece três instrumentos fundamentais de planejamento: o Plano Plurianual; a Lei de Diretrizes Orçamentárias e a Lei Orçamentária anual. Os três instrumentos se interligam, dotando a gestão pública de um processo orçamentário racional a curto, médio e longo prazo. Nesse contexto o orçamento participativo passa a ser o instrumento democrático que permite aos cidadãos participarem do processo pela organização social, permitindo às prefeituras estabelecerem limites e critérios para compartilhar o poder de decisão com os moradores das diversas regiões de um município. O presente artigo constitui-se como um ensaio de revisão teórica, englobando pontos como o orçamento tradicional, plano plurianual, Lei de Diretrizes Orçamentárias, orçamento participativo e democracia. Conclui-se que para que haja êxito em sua elaboração, execução e controle do orçamento participativo é necessário a conscientização da população sobre a importância da participação social efetiva, de modo livre e universal nas assembleias e fóruns de discussão para a tomada de decisão orçamentária. Ao atuar efetivamente no orçamento participativo, o cidadão deixa de ser um mero coadjuvante para ser protagonista e tomador de decisões sobre os recursos/investimentos públicos. A efetiva realização e implementação do orçamento participativo podem ser visualizadas como um fortalecimento da democracia na gestão municipal.
\end{abstract}

Palavras-chave: Orçamento Participativo. Gestão Pública. Democracia. Politicas Públicas. Cidadão

\section{The Participatory Budget in Public Management's}

\begin{abstract}
The Federal Constitution establishes three fundamental planning instruments: the Plurianual Plan; The Budget Guidelines Law and the annual Budget Law. The three instruments interconnect, providing public management with a rational budget process in the short, medium and long term. In this context, participatory budgeting becomes the democratic instrument that allows citizens to participate in the process through social organization, allowing municipalities to establish limits and criteria for sharing decision-making power with residents of different regions of a municipality. This article is a theoretical review essay, encompassing points such as the traditional budget, the multi-annual plan, the Budget Guidelines Law, participatory budgeting and democracy. It is concluded that for the success of its elaboration, execution and control of the participatory budget, it is necessary to raise public awareness about the importance of effective social participation, in a free and universal way in assemblies and discussion forums for budget decision making. When acting effectively in the participatory budget, the citizen ceases to be a mere adjunct to be a protagonist and decision maker on public resources / investments. The effective implementation and implementation of participatory budgeting can be seen as a strengthening of democracy in municipal management.
\end{abstract}

Keywords: Participatory Budgeting. Public administration. Democracy. Public policy. Citizen

\footnotetext{
${ }^{1}$ Universidade Vale do São Francisco - UNIVASF. Contato: sonylins_joy@ hotmail.com;

${ }^{2}$ Universidade Vale do São Francisco - UNIVASF. Contato: teacher.jk@ hotmail.com;

${ }^{3}$ Universidade Vale do São Francisco - UNIVASF. Contato: mariolopestb@hotmail.com;

${ }^{4}$ Universidade Vale do São Francisco - UNIVASF. Contato: mayara_mmm@ @otmail.com;

${ }^{5}$ Administrador pela Estácio de Sá (2005); MBA em Gestão Estratégica de Negócios pela Escola de Engenharia Eletromecânica da Bahia; Especialista em Marketing Institucional pela Faculdade São Francisco de Juazeiro; Mestre em Gestão de Políticas Públicas da Universidade Federal do Recôncavo da Bahia . Administrador da Universidade Federal do Vale do São Francisco lotado na Assessoria de Comunicação; Professor da Faculdade São Francisco de Juazeiro: Graduação em Administração e em Comunicação Social e Pós Graduação em Gestão Estratégica e em Marketing; Professor da Universidade Federal do Vale do São Francisco: Pós Graduação em Gestão Pública. Contato: prof.caffe@gmail.com
} 


\section{Introdução}

O Gestor seja ele municipal estadual ou federal; para desenvolver suas atividades e atingir a satisfação do interesse público, necessita cada vez mais de recursos, principalmente aqueles de natureza financeira. As demandas da sociedade, sempre crescentes, são influenciadas pelas transformações sociais, econômicas e tecnológicas e, também, pelo estabelecimento de um Estado Democrático, que vem possibilitando aos cidadãos reivindicar a satisfação do interesse coletivo. (ABRUCIO, 1998)

No entanto, para dispor desses recursos para que o gestor público possa exercer e desempenhar suas funções não é o bastante; pois se faz necessário o planejamento desde a geração e arrecadação até a aplicação dos recursos de modo que as disponibilidades possam ter sua utilização correta; evitando assim danos, percas e desvios dessas verbas. (AGRA, 2010)

Sendo assim, é importante citar que nas últimas décadas, foi registrado o ressurgimento da importância no campo do conhecimento denominado políticas públicas. Vários fatores contribuem para maior visibilidade desta área, sendo os principais, a adoção de políticas públicas restritivas aos gastos e as novas visões sobre o papel do governo. (DIAS, 2000)

Com intuito de que o Orçamento Participativo (OP) seja um forte mecanismo governamental de democracia participativa que permite aos cidadãos influenciar ou decidir sobre os orçamentos públicos, de investimentos de prefeituras municipais, através de processos da participação da comunidade em geral. (GREY, 1996)

Diante deste cenário, o $\S 1^{\circ}$ do artigo 74 da Constituição Federal define que "a lei estabelecerá as diretrizes e bases do planejamento e desenvolvimento nacional equilibrado, o qual incorporará e compatibilizará os planos nacionais e regionais de desenvolvimento". (HARVEY, 1991)

Para operacionalizar o conceito de planejamento criado, a Constituição Federal designa três instrumentos: Plano Plurianual, Lei de Diretrizes Orçamentárias e Lei Orçamentária Anual; tais instrumentos são atos normativos que podem ser interligados e determinam que o setor público deve criar um processo de planejamento orçamentário, 
preconizando assim um plano de governo mais transparente e coerente que pode ser aplicado a longo, médio e curto prazo. (DALLARI, 1999)

Por se tratar de um instrumento democrático; o orçamento participativo deve ser considerado como uma importante experiência de mecanismo de envolvimento da sociedade ao processo de escolha pública no Brasil, permitindo assim que os cidadãos participem do processo pela organização, e ás prefeituras a compartilhar o poder decisório com os munícipes da região. (GUSTIN, 2008)

O presente estudo trata-se de uma revisão teórica, focando no tema do orçamento participativo e tendo como base, dentre outros autores citados ao longo do estudo, a legislação em Políticas Públicas vigentes.

O orçamento participativo, deve estar diretamente relacionada à população da região, especificas a cidade em questão, sempre respeitando as prioridades apresentadas durante as assembleias, permitindo que os cidadãos assumam "uma função executiva" englobando o levantamento e fiscalização das ações a serem priorizadas.

\section{Políticas Públicas}

O conceito de Políticas Públicas possui sentidos e pontos de vista diferente; no sentido político, aceita-se a política pública como um processo de decisão, no qual existem naturalmente conflitos de interesses. É através das políticas públicas que o governo decide o que fazer ou não. Já do ponto de vista administrativo: as políticas públicas são um conjunto de projetos, programas e atividades realizadas pelo governo. (ABRUCIO, 1998)

Embora a literatura apresente diversas definições para o termo, podemos dizer que: Políticas Públicas são conjuntos de programas, ações e atividades desenvolvidas pelo Estado diretamente ou indiretamente, com a participação de entidades públicas ou privadas, que visam assegurar determinado direito de cidadania ou para determinado seguimento social, cultural, étnico ou econômico. As mesmas devem assegurar direitos constitucionalmente ou que se afirmam e são reconhecidas por parte da sociedade e/ou pelos poderes públicos enquanto novos direitos das pessoas, comunidades, coisas ou outros bens materiais ou imateriais. (Secretaria do Meio Ambiente, 2017). 
De acordo com o Sebrae (Serviço Brasileiro de Apoio às Micro e Pequenas Empresas), o conceito de políticas públicas diz respeito a um conjunto de ações e decisões do governo, voltadas para a solução de problemas encontrados na sociedade.

A Política Pública possui dois elementos fundamentais:

a) Intencionalidade pública - motivação para o estabelecimento de ações para tratamento ou para resolução de um problema;

b) Problema público - diferença entre uma situação atual vivida (status quo) e uma situação ideal possível à realidade coletiva.

São constituídas por instrumentos de planejamento, execução, monitoramento e avaliação, encadeados de forma integrada e lógica, da seguinte forma:

1.Planos

2. Programas;

3. Ações

4. Atividades.

Os planos estabelecem diretrizes, prioridades e objetivos gerais a serem alcançados em períodos relativamente longos. Neste contexto, é onde são atribuídos os referendos aos Orçamentos Públicos, sendo eles participativos ou não. (FERREIRA, 1991)

A Lei Complementa n. ${ }^{\circ} 131$ (Lei da Transparência), de 27 de maio de 2009, assegura quanto à participação da sociedade, e assim determina:

\footnotetext{
I - incentivo à participação popular e realização de audiências públicas, durante os processos de elaboração e discussão dos planos, lei de diretrizes orçamentárias e orçamentos;"

II - liberação ao pleno conhecimento e acompanhamento da sociedade, em tempo real, de informações pormenorizadas sobre a execução orçamentária e financeira, em meios eletrônicos de acesso público;
}

Sendo regulamentada pelo Decreto $\mathrm{n}^{0} \mathbf{7 . 1 8 5}$, de 27 de maio de 2010, "que define o padrão mínimo de qualidade do sistema integrado de administração financeira e controle, nos termos do inciso III, parágrafo único do art. 48 da LRF. A Secretaria do Tesouro Nacional também editou a Portaria $\mathrm{n}^{\circ} 548$, de 22 de novembro de 2010, que estabelece os requisitos mínimos de segurança e contábeis do sistema integrado de administração financeira e controle 
utilizado no âmbito de cada ente da Federação, adicionais aos previstos no Decreto $\mathrm{n}^{\circ} 7.185$, de 27 de maio de 2010".

\title{
Conceitos de Cidadania
}

O conceito de cidadania, se renova ou deveria se renovar constantemente diante das transformações sociais; para tal razão então é possível afirmar que cidadania não é uma idéia estática, mas dinâmica. Neste sentido, destaca-se:

\begin{abstract}
O conceito contemporâneo de cidadania se estendeu em direção a uma perspectiva na qual cidadão não é apenas aquele que vota, mas aquela pessoa que tem meios para exercer o voto de forma consciente e participativa. Portanto, cidadania é a condição de acesso aos direitos sociais (educação, saúde, segurança, previdência) e econômicos (salário justo, emprego) que permite que o cidadão possa desenvolver todas as suas potencialidades, incluindo a de participar de forma ativa, organizada e consciente, da construção da vida coletiva no Estado democrático. (BONAVIDES, 1988).
\end{abstract}

Cidadania é o exercício dos direitos e deveres civis, políticos e sociais estabelecidos na Constituição de um país.

A idéia atual de cidadania passou por diversas mutações ao longo dos tempos. A cidadania seria não apenas um instrumento pertencente ao indivíduo de participação ativa nas decisões governamentais, mas também um meio de influência na gestão pública, de modo a reformá-la à medida que as opiniões do povo acerca da sociedade e m que vivem se transformam. Desta forma, pode-se visualizar que as concepções sobre cidadania foram progredindo, e, com isso, cresceu também o poder da participação popular na administração pública, originando a chamada democracia participativa. (DU GAY, 1995)

O conceito de cidadania também está relacionado com o país onde a pessoa exerce os seus direitos e deveres. Assim, a cidadania brasileira está relacionada com o indivíduo que está ligado aos direitos e deveres que estão definidos na Constituição do Brasil. (GENTRO, 2000)

Para ter cidadania brasileira, a pessoa deve ter nascido em território brasileiro ou solicitar a sua naturalização, em caso de estrangeiros. No entanto, os cidadãos de outros países 
que desejam adquirir a cidadania brasileira devem obedecer todas as etapas requeridas para este processo. (GENRO, 1997)

A Constituição da República Federativa do Brasil, promulgada em 5 de outubro de 1988, pela Assembleia Nacional Constituinte, composta por 559 congressistas (deputados e senadores), consolidou a democracia, após longos anos da ditadura militar no Brasil. Entre alguns dos principais deveres e direitos dos cidadãos está:

\section{Deveres do cidadão}

- Votar para escolher os governantes;

- Cumprir as leis;

- Educar e proteger seus semelhantes;

- Proteger a natureza;

- Proteger o patrimônio público e social do País.

\section{Direitos do cidadão}

- Direito à saúde, educação, moradia, trabalho, previdência social, lazer, entre outros;

- O cidadão é livre para escrever e dizer o que pensa, mas precisa assinar o que disse e escreveu;

- Todos são respeitados na sua fé, no seu pensamento e na sua ação na sociedade;

- O cidadão é livre para praticar qualquer trabalho, ofício ou profissão, mas a lei pode pedir estudo e diploma para isso;

- Só o autor de uma obra tem o direito de usá-la, publicá-la e tirar cópia, e esse direito passa para os seus herdeiros;

- Os bens de uma pessoa, quando ela morrer, passam para seus herdeiros;

- Em tempo de paz, qualquer pessoa pode ir de uma cidade para outra, ficar ou sair do país, obedecendo à lei feita para isso.

\section{Orçamento Público e Orçamento Participativo}

O processo orçamentário deve ser tratado como um sistema ou ciclos, onde as determinações relevantes do eleitorado sejam transformadas em projetos e programas, visando 
satisfazer as demandas do bem público. Embora, segundo Santos e Garrido, tal mecanismo seja muito questionado quanto a falta de transparência na aplicação segura do mesmo (TENÓRIO, 1998).

Dessa forma, deve ser reconhecido que todos os envolvidos no processo têm responsabilidades no ato de determinar a aplicação da receita nos gastos públicos apresentados ao Legislativo, determinando o orçamento público como documento, objetivando garantir o alcance de metas propostas, para com a sociedade como um todo. (CARMO CARVALHO, 1997)

A Constituição federal determina que o Orçamento, sendo ele participativo ou não, deve ser votado e aprovado até o final de cada ano de legislatura, ou seja, 15/12 de cada ano, embasado na legislação brasileira por meio da Constituição Federal (art. 165, §8º e Lei n $^{\circ}$ 4.320/64 (art. $\left.7^{\circ}\right)$.

\section{Orçamento tradicional}

O orçamento tradicional é aquele que, demonstra os gastos de forma superficial, não especificando dados importantes ás finanças públicas. Nesse tipo de orçamento, não se faz necessária a criação, ampliação e demonstração dos objetivos a serem alcançados no exercício financeiro. Esta ferramenta tem como preocupação os meios e não os fins, ou seja, um documento onde constam apenas as despesas fixas e a previsão de receita, sem que haja planejamento das ações do governo. Trata-se apenas de um documento contábil - financeiro, um documento de previsão de receita e de autorização de despesas. (GONÇALVES, 2005; CARVALHO,2000)

\section{Orçamento programa}

Implementado no Brasil a partir da Lei 4320/64 e o Decreto-Lei 200/67, o orçamentoprograma é um orçamento vinculado ao planejamento e programação inseridos num contexto maior de sistema de gestão. Para Giacomini (1997, p. 54-55), os elementos essenciais do orçamento-programa são: 
Os objetivos e propósitos perseguidos pela instituição e para cuja consecução são utilizados os recursos orçamentários;

Os programas, isto é, os instrumentos de integração dos esforços governamentais no sentido da concretização dos objetivos;

Os custos dos programas medidos pela identificação dos meios ou insumos (pessoal, material, equipamentos, serviços, etc.) necessários para a obtenção dos resultados; e, Medidas de desempenho com a finalidade de verificar as realizações (produto final) e os esforços despendidos na execução dos programas.

O orçamento-programa é o processo onde devem constar: aprovação, execução e ainda avaliação do nível de cumprimento do programa de governo para cada período orçamentário, tendo em vista as perspectivas de médio e longo prazo.

A Constituição Federal - CF/8 implantou de forma definitiva o orçamento - programa no nosso País, ao estabelecer a normatização da matéria orçamentária através do PPA, da LDO e da LOA, evidenciando o extremo cuidado do constituinte em relação ao planejamento das ações do governo.

\section{Plano plurianual}

O Plano Plurianual é uma ferramenta de planejamento estratégico onde devem constar as ações governamentais a serem aplicadas no período de 04 (quatro) anos, considerando o planejamento de médio prazo. O projeto do PPA deve ser enviado ao Presidente da República ao Congresso Nacional até 31 de agosto do primeiro ano do mandato do gestor, ou seja, 4 meses antes do encerramento da sessão Legislativa Estadual e Municipal.

O PPA deve contemplar, de acordo com o art.165 da Constituição $\S 1^{\circ}$ da Constituição Federal, as diretrizes, objetivos e metas da administração pública para as despesas de capital e outras despesas decorrentes da região.

A Constituição Federal, estabelece também que, desde a sua divulgação, a elaboração do plano plurianual como o principal instrumento de planejamento administrativo. No entanto somente com a publicação da Lei Complementar 101 essa ferramenta teve como obrigatoriedade a sua aplicação, como pode-se ver no próprio texto legal as seguintes definições (GONÇALVES, 2005), o chamado DOM: 
Diretrizes: representam o conjunto de critérios de ação e de decisão que deve disciplinar e orientar os diversos aspectos envolvidos no processo de planejamento;

Objetivos: são os resultados que se pretende alcançar com a realização das ações governamentais;

Metas: referem-se à especificação e quantificação física dos objetivos estabelecidos.

O Plano Plurianual é uma tentativa de integração do planejamento com o orçamento tendo sua vigência abrangendo o período da gestão seguinte, visando assegurar a continuidade dos objetivos traçados pela administração, evitando assim que ocorram interrupções bruscas ao planejamento apresentado. Para tanto, o mesmo não pode ser elaborado apenas para atender às determinações legais, mas deve também se atentar para a busca do equilíbrio econômico e financeiro de cada entidade que compõem o município em questão, de modo que os resultados possibilitem que o déficit público seja contido e revertido. (GUSTIN, 2008)

O equilíbrio das contas de cada município é decisivo para a economia nacional, visto que grande parte da dívida pública é gerada na esfera municipal.

Em sua elaboração deve-se levar em conta as características distintas à administração pública, levando em conta que o Estado não tem em suas atividades o fim lucrativo como na iniciativa privada. Para BOBBIO, não deve-se exigir do administrador apenas a legitimidade eleitoral e postura ética, mas também que tenha preparo técnico e visibilidade dos problemas enfrentados pela região, para buscar soluções para as demandas que forem impostas pelos cidadãos e ainda que compreenda que uma má gestão municipal influi em todo o cenário econômico do município. (BARRETO, 1999; BOBBIO, 1992)

Podemos concluir então que, o Plano Plurianual é o demonstrativo de que todas as ações a serem realizadas pelo gestor devem ter um instrumento de transformação econômicosocial e ser uma ponte entre a situação atual e aquela que se busca atingir durante a administração. (BRESSER, 1998b)

\section{Lei de Diretrizes Orçamentárias (LDO)}

A Lei de Diretrizes Orçamentárias (LDO) representa uma colaboração no sentido de tornar o processo orçamentário mais transparente para a população; estabelecendo metas e prioridades para o exercício financeiro municipal, orientando na elaboração do orçamento e 
dispondo sobre alterações na legislação tributária podendo estabelecer política de aplicação em agências financeiras de formento. Contribuindo assim, numa participação ampla do Poder Legislativo na elaboração das finanças públicas; estabelecendo metas do Plano Plurianual e na elaboração do Orçamento Geral da União.

Silva (1993 apud GONÇALVES, 2005, p. 37-38) afirma que a LDO surgiu como uma novidade no processo orçamentário, servindo às seguintes finalidades:

- Fixar as metas e prioridades a serem observadas pela administração no exercício seguinte, resguardando a coerência e a continuidade do Plano Plurianual que tem de se ater aos objetivos principais fixados nesse instrumento;

- Condicionar a representação das emendas ao projeto de lei orçamentária, ainda dentro da mesma filosofia;

- Tornar mais fácil a análise e discussão a respeito da hierarquização das prioridades, por não estar limitada, diretamente, aos aspectos financeiros;

- Definir as metas necessárias e ideais para serem compridos pelo órgão público em favor da coletividade;

- Eliminar a prática de cortes lineares nos orçamentos dos diversos órgãos em face da escassez dos recursos disponíveis, subjugando-os à escala de prioridades fixadas na LDO. Esse ponto pode ser considerado uma decorrência do anterior;

- Reverter uma tendência negativa de se encarar o processo de elaboração do orçamento como um fim em si mesmo, ajustando-o à correta perspectiva de ser um instrumento auxiliar do planejamento governamental, assumindo uma posição estratégica no contexto das problemáticas da população.

Em suma, podemos dizer que, a LDO constitui um referencial básico para a avaliação da eficácia quanto ao cumprimento das metas e objetivos impostos.

\section{Orçamento Publico}

O orçamento público é um documento legal, aprovado por lei que deve conter informações com a previsão de receitas e despesas á serem realizadas por uma determinada gestão, em um determinado exercício anual, onde devem conter origem e destinação da receita informada. (BRESSER, 1997)

Com a inovação administrativa, surge então o Orçamento Participativo, para Baleeiro (1987),

O orçamento público "é o ato pelo qual o Poder Executivo prevê e o Poder Legislativo autoriza por certo período de tempo, a execução das despesas destinadas ao funcionamento dos serviços públicos e outros fins adotados pela política econômica ou geral do país, assim como a arrecadação das receitas já criadas em lei. 
Segundo SANCHES (1997), princípio orçamentário é

Um conjunto de proposições orientadoras que balizam os processos e as práticas orçamentárias, com vistas a dar-lhe estabilidade e consistência, sobretudo ao que se refere a sua transparência e ao seu controle pelo Poder Legislativo e demais instituições da sociedade.

\section{Orçamento Participativo}

O orçamento participativo é um instrumento que existe para permitir que os cidadãos participem do processo apresentado pelas prefeituras, o que permite às prefeituras estabelecerem limites e critérios no compartilhamento do poder de decisão com os moradores da cidade; porém o que o cidadão comum não sabe é que pode auxiliar diretamente nessa definição, apontando quais são as prioridades para a aplicação dos recursos do orçamento de seu município. Nas cidades onde existem esse tipo de instrumento, o orçamento participativo, é criada uma Comissão de representantes da comunidade que, em Assembleias e/ou reuniões, discutem com membros da prefeitura ou do governo estabelecendo quais áreas devem receber maior investimento. Tais reuniões devem ser públicas, abertas, periódicas e as decisões tomadas durante as mesmas, devem ser consideradas e apresentadas junto a proposta da Lei Orçamentária Anual (LOA), a qual deverá ser enviada para a assembleia legislativa no caso dos Estados, ou Câmara Municipal, no caso dos municípios. (GUERREIRO, 1997)

A LOA tem como função fundamental, levantar os valores reais das receitas e autorizar as despesas do Governo de acordo com a previsão da arrecadação municipal realizada durante o exercício financeiro, tratando-se de uma ferramenta de cidadania que tem como objetivo o fortalecimento dos recursos públicos de suma importância na constituindo assim uma experiência nova no contexto de políticas publicas no Brasil. (SANTOS, 2015; DOIMO, 1995).

Salientando que, o Poder Executivo faz Decretos chamados de Contingenciamento, nos quais devem ser autorizados os limites financeiros e orçamentários pelo Congresso, dando limites as despesas aprovados na Lei do Orçamento. 
Segundo Souza (2001), as visões sobre o orçamento participativo são diversas dificultando uma síntese, porém como tentativa de unir todas as respostas agregando valor informacional á elas, a referida autora realizou as seguintes sínteses:

- $\quad$ Na gestão: existe a visão de que o orçamento participativo é: a) gestão urbana com os pobres; b) mecanismo de gestão conjunta dos recursos públicos através de decisões compartilhadas sobre a alocação dos recursos orçamentários; c) modelo de gestão urbana mais do que uma política pública; e d) processo de gestão fiscal social.

- $\quad$ Na educação, a maior parte da literatura considera o orçamento participativo um processo educativo que envolve todos os atores locais importantes - prefeito, burocratas, vereadores, movimentos sociais -, assim como as instituições nas quais esses atores operam. Essa visão é tributária do pensamento de Stuart Mill sobre o papel educativo do governo local.

- $\quad \mathrm{Na}$ política, as visões são bastante diversas. O orçamento participativo é: a) uma política pública em que os que têm poder o cedem para os grupos em desvantagem; b) uma forma de radicalizar a democracia e o resultado de uma grande vontade política, capaz de permitir a construção de uma cultura política, que aumente a conscientização sobre a cidadania, e de melhorar as condições de vida da população; c) uma das formas correntes de globalização contra-hegemônica; d) uma forma de combinar democracia representativa com participação; e, e) um instrumento para superar os limites da democracia representativa através de mecanismos que ampliem a mobilização da sociedade civil para além do corporativismo e da simples consulta. Contrariando as visões correntes sobre o orçamento participativo, Dias (2000) argumenta que a experiência tem sido uma forma de o Executivo municipal sobrepor-se ao Legislativo. Ainda no território do papel político do orçamento participativo, aparece na literatura a visão de que o programa aumenta a transparência, accountability e a credibilidade dos governos e seus participantes. $\mathrm{O}$ orçamento participativo também é constantemente mencionado como forma de eliminar (ou diminuir) o clientelismo, o autoritarismo e o patrimonialismo. Assim, embora com opiniões altamente divergentes, a literatura chega quase sempre à mesma conclusão: o orçamento participativo está mudando a vida política das regiões onde se instala.

- $\quad$ Na mudança social: o orçamento participativo permite: a) a distribuição mais justa de recursos escassos em uma sociedade altamente desigual; b) um instrumento inovador para a reconstrução da vida pública; c) nova forma de relacionamento entre o poder público local, as organizações populares e o resto da sociedade, a fim de atender às demandas dos segmentos mais pobres da população; d) o fortalecimento do associativismo urbano e do relacionamento entre as associações comunitárias e os moradores dos distritos; e) uma forma justa de decidir sobre a alocação de recursos.

Baseado no contexto participativo do orçamento podemos dizer que é imprescindível a existência de etapas realizadas de forma sucessiva encadeando uma lógica na tomada de decisões, considerando-se a etapa de elaboração, a discussão do orçamento popular, sua apreciação, execução e avaliação. Sendo assim, o OP constitui-se de processos criados a partir de consultas e debates realizados no âmbito municipal. (JACOBI, 2000) 
De acordo com Gonçalves (2005), o orçamento participativo representa um grande passo no sentido do aperfeiçoamento político, não somente os parlamentares participam das decisões sobre finanças e políticas públicas ao mesmo tempo em que a população se organiza e a sociedade civil assume um papel ativo na movimentação orçamentária, passando a ser não apenas um mero espectador da situação. (Teixeira, 2016)

Ainda, para Gonçalves (2005), a democracia é um importante instrumento de avaliação e aplicação de recursos, é a melhor forma que visa facilitar que o cidadão exerça seus direitos e deveres participativos na definição dos rumos de ação governamental.

\section{Orçamento Participativo e Receita}

Pouco debatidos nas Prefeituras do país, o vínculo entre orçamento e receita aproximada é o instrumento que gera maior problemas as mesmas durante a administração; pois nele deveriam estar propostas todos os compromissos do executivo (COSTA, 2009).

O orçamento deve prever não só os recursos arrecadados como também os gastos com pagamento de pessoal, manutenção da cidade, serviços sociais e com novos investimentos em obras. Demonstrando assim, o comprometimento de receitas que permitam que as despesas sejam de fato executadas. O que ocorre na maioria das vezes os orçamentos apresentados não são claros, transparentes ou funcionais mas, verdadeiras peças de ficção, maquiadas e de difícil compreensão, tanto pela população quanto pela própria Câmara Municipal responsável pela sua aprovação, e muitas vezes até mesmo ininteligível pelo próprio prefeito. (COSTA, 2009).

Um orçamento razoável deve ser claro, limpo e transparente proporcionando uma fácil leitura e interação por parte da população, que visa saber os reais planos de execução e utilidade do mesmo. Para tanto, faz-se necessária reuniões onde o mesmo seja apresentado pelo poder público e discutido junto á população, demarcando as prioridades de execução, dando assim a oportunidade de participação dessa população. (LOUREIRO, 1998)

A principal função do OP é ser transparente, reduzir falhas, proibir abusos e como principal função regularizar as receitas, mantendo o comprometimento do Poder Público perante a população. (ABRUCIO, 1998) 
Normalmente, o que se pode prever como receita para tributos federais são o ICMS Imposto sobre Circulação de Mercadorias - estadual e Fundo de Participação dos Municípios (FPM) federal; com provisões baseadas na arrecadação do ano anterior (COSTA, 2009).

Já para o montante demonstrativo das receitas tributárias municipais que devem constar no orçamento definidas pela Constituição podemos citar o IPTU - Imposto Predial e Territorial Urbano, o ISS - Imposto sobre Serviços de Qualquer Natureza e o ITBI - Imposto sobre Transmissão" Inter Vivos", a Qualquer Título, por Ato Oneroso, de Bens Imóveis, por Natureza ou Acessão Física, e de Direitos Reais sobre Imóveis. Impostos esses que são de obrigatoriedade municipal, devendo ter suas regras propostas pelo executivo e aprovadas pela Câmara Municipal. (MARE, 1997; LÜCHMANN, 2002).

Existe uma grande dificuldade nos municípios na cobrança e destinação dos valores arrecadados nos impostos e ainda, a aplicabilidade dos mesmos pois oneram a população. Para tanto é importante que haja transparência na apresentação do orçamento junto à população para que entendam a arrecadação e aplicabilidade da mesma na prestação de serviços (COSTA, 2009; MENDES, 2008).

Para tanto podemos afirmar que se faz necessário o envolvimento da população na discussão prévia do orçamento, tornando-os mais responsáveis pelo pagamento e fiscalização da arrecadação de tributos (MELO, 2017).

De acordo com BITTAR (2007);

Para o crescimento da receita própria municipal, o ponto de partida correto é a discussão sobre o que deve ser feito na cidade. Colocados os valores necessários na proposta orçamentária, o passo seguinte é a aprovação por parte da Câmara Municipal dos projetos de lei tributários que possam garantir a obtenção dessa receita própria suficiente para cobrir a diferença entre as necessidades e as transferências que vem do Estado e do Governo Federal.

\section{Orçamento Participativo como Instrumento Democrático}

Desde o início do processo de colonização brasileira tinha-se um Estado onde havia a prevalência das práticas clientelistas e de favorecimentos às classes dominantes economicamente, as quais, mesmo de forma mais amena, ainda perduram atualmente. Deste 
modo, sempre houve governantes e modelos estatais que faziam do Estado algo que lhes pertencia, que fazia parte de seu patrimônio particular (AGRA,2010).

O orçamento participativo é um instrumento de democracia participativa. Como ensina Norberto Bobbio (2000), a democracia é dinâmica e está em permanente transformação, é sempre reinventada, tornando-se evolutiva e qualitativa por ultrapassar a si própria.

Para tanto, a associação entre Estado, sociedade e democracia participativa mostra-se de suma importância para explicar a trajetória da origem da cidadania, da democracia e do atual modelo de Estado. Ressalta-se ainda, que da união destes três entes pode resultar o surgimento de um Estado baseado na justiça e na igualdade social, onde se idealiza a concretização dos direitos cidadãos, e, conseqüentemente, a presença de um governo firmado numa cogestão realizada entre Estado e sociedade. (Canotilho, 1993)

A consolidação da democracia é também, uma dos principais papéis do Orçamento Participativo, representando o atendimento às necessidades populares por meio da definição da própria sociedade sobre suas prioridades. Dessa forma, os recursos públicos, que são escassos, destinam-se de forma organizada e redefinida às ações escolhidas como principais pela comunidade, fortalecendo as decisões do povo sobre como, para que, de que forma e por que devem ser governados. (Pereira, 2014)

De acordo com Avritzer (2000) é possível, portanto, afirmar que a teoria democrática que se tornou hegemônica na primeira metade do século XX possui três elementos:

1) O primeiro desses elementos consiste na noção de que as diferenças culturais não podem ser resolvidas por meio da argumentação. Consequentemente, a única forma de se fazer política democrática seria deixando tais diferenças de lado. Desse modo, a argumentação de uma condição pluralista seria deixada de fora da política.

2) O segundo elemento no processo de afirmação de uma concepção de democracia está relacionado à defesa de uma inter-relação estreita entre administração não participativa e preservação da complexidade. De acordo com tal concepção, é a redução das demandas e a capacidade da burocracia de segui-las racionalmente que determina a eficiência. Mais uma vez, o processo de argumentação e troca de informação intrínseco as formas participativas de administração é excluído do campo da política.

3) O terceiro elemento da afirmação de uma concepção de deliberação é a idéia de que o processo eleitoral consiste na aferição de preferências individuais préformadas.(...) Mais uma vez, o elemento argumentativo da discussão democrática da diferença de interesses e/ou valores é negado. No entanto, o fato interessante em relação à teoria democrática do final do século XX é como todos os três elementos aqui sintetizados de uma concepção de deliberação irão entrar em crise profunda. 
Segundo Baquero (2002); para 80,4\% da população a visão de democracia se apresenta como "mesmo com problemas, a melhor forma de governo". Portanto, podemos afirmar que a sociedade em geral apoia a gestão de forma democrática. Mas, conforme Baquero explica apoio à democracia no Brasil, no ano de 2000 era menor, com cerca de 39\% de aprovação popular; demonstrando dessa forma que a sociedade brasileira era a nação com o menor índice de apoio à democracia entre os países da América Latina; demonstrando assim um grande nível de rejeição de formas autoritaristas de governo.

No Brasil, o modelo adotado é o Orçamento-Programa, que define os gastos segundo programas de trabalho detalhados por órgão, função, até o nível de projeto ou atividade a ser executado (PIRES, 2001). Essa técnica orçamentária foi introduzida na esfera federal pelo Decreto-Lei ${ }^{\circ}$ 200, de 23 de fevereiro de 1967, que menciona o orçamento-programa como plano de ação do governo federal. Contudo, o marco legal que cristalizou a adoção do orçamento-programa no Brasil foi a Portaria da Secretaria de Planejamento e Coordenação da Presidência da República $\mathrm{n}^{\circ}$ 9, de 28 de janeiro de 1974, que instituiu a classificação funcional-programática e vigorou até 1999. A partir do exercício de 2000, houve sua revogação, pela Portaria no 42, de 14 de abril de 1999, do então Ministério do Planejamento, Orçamento e Gestão (MPOG), que instituiu uma classificação funcional e remeteu a estrutura programática aos planos plurianuais de cada governo e esfera da federação.

Apesar d e identificar um apoio diluído da população à democracia, BAQUERO (2002) constatou no Brasil, que o nível de insatisfação é significativo, o wur corresponde a $62,4 \%$ dos participantes respondentes de uma pesquisa realizada pelo referido autor em 2000 , onde afirmaram estarem pouco ou nada satisfeitos com a atuação do governo democrático no país. Dado este preocupante, uma vez que a insatisfação da população pode vir a comprometer o avanço da democracia no país.

A consolidação da democracia é também uma dos principais papéis do Orçamento Participativo, representando o atendimento às necessidades populares por meio da definição da própria sociedade sobre suas prioridades. Dessa forma, os recursos públicos, que são escassos, destinam-se de forma organizada e predefinida às ações escolhidas como principais pela comunidade, fortalecendo as decisões do povo sobre como, para que, de que forma e por que devem ser governados. (WILGES, 2006) 
O exercício da democracia é uma conquista, segundo ARENDT (1998) "não existe participação suficiente ou acaba. Não existe como dádiva ou como espaço preexistente. Existe somente na medida de sua própria conquista”.

Em seu discurso Pedro Arendt (1998), afirma que:

\begin{abstract}
Participação é conquista para significar que é um processo, no sentido legítimo do termo: infindável, em constante vira-ser, sempre se fazendo conquista processual. Não existe participação suficiente, nem acabada. Participação que se imagina completa, nisto mesmo começa a regredir.
\end{abstract}

Portanto, para garantir avanços e conquistas no sistema democrático faz-se necessária a participação contínua para evoluir e avançar na avaliação dos processos de gestão social e democrático no país. Dagnino (2002, p. 282) "[...] o impacto da sociedade civil sobre o desempenho do Estado (governance) é uma tarefa que não pode se apoiar num entendimento abstrato dessas categorias como segmentos separados, mas sim contemplar tudo o que as articula e as difere, inclusive o que as une e opõe sendo aqui designado como projetos políticos".

DAGNINO(2002) defende que a participação social no governo tem muitas limitações mas, para SANTOS e AVRITZER (2003), o orçamento participativo deve constituir uma ferramenta de participação democrática, garantindo que a população seja ouvida e tenha poder significativo nas tomadas de decisões governamentais.

Durante seus 3 mandatos no Governo, os petistas tornaram mais comuns os instrumentos de participação democrática nos âmbitos estaduais e federais do país, considerando assim que a democracia foi exercida de forma mais efetiva no país. Tendo como base os estudos realizados por SANTOS e VRITZER (2003) sobre orçamento participativo aplicados na cidade de Porto Alegre foi concluído que orçamento participativo é um instrumento democrático, que traz para a sociedade uma experiência positiva e valoriza a prática da democracia participativa.

Para GUSTIN (2008), o orçamento participativo se manifesta em três das suas características principais:

(1) participação aberta a todos os cidadãos sem nenhum status especial atribuído a qualquer organização, inclusive as comunitárias; 
(2) combinação da democracia direta e representativa, cuja dinâmica institucional atribui aos próprios participantes a definição das regras internas e

(3) alocação dos recursos para investimentos baseado na combinação de critérios gerais e técnicos, ou seja, compatibilização das decisões e regras estabelecidas pelos participantes com as exigências técnicas e legais da ação governamental, respeitando também os limites financeiros.

Para CARVALHO (2006) a primeira forma bem sucedida de combinação entre elementos da democracia representativa e da democracia participativa deve acontecer no nível local, onde cidadãos participam de um processo de negociação e debates sobre as prioridades do município na distribuição de bens públicos. Visando a distribuição justa desses bens públicos e a negociação sobre o acesso a esses bens.

Portanto pode-se afirmar que o orçamento participativo é constituído a partir da ampliação do processo democrático e o mesmo deve favorecer a participação dos cidadãos locais na gestão pública, não apenas a título de informação, mas na atuação no processo decisório (FURTADO, 2014).

Por fim, orçamento participativo nada mais é do que um instrumento de democracia voltado para a gestão social, e a mesma deve possibilitar uma mediação entre o governo e a sociedade constituindo um exercício democrático (PIOVESAN, 2000).

\section{Considerações Finais}

Historicamente, a administração do dinheiro público no Brasil é tratada como algo inacessível a população, sendo que o mesmo só pode ser criado, analisado e discutido por técnicos internos ao governo; já o Orçamento Participativo é uma ferramenta contrária a esse movimento que tem o intuito de suprir a falta de informação e envolvimento da população (OLIVEIRA, 2006).

Podemos afirmar que o orçamento participativo tem grande importância para a demonstração e aplicabilidade da democracia na administração pública dos municípios, 
visando popularizar a ações de participatividade dos cidadãos com intuído de utilização racional dos recursos públicos.

Salientamos ainda que, o OP é materialização do que é proposto na Teoria de Democracia representativa, não limitando a participação popular somente ao voto (MEZZONO 2000).

No Brasil, a aplicabilidade e abertura da gestão à tal versão democrática mais participativa é um paradigma para as administrações, pois o orçamento participativo é a realização de um ideal de participação popular.

O orçamento participativo é um instrumento que tem como objetivo permiti a visualização transparente e integral dos processos, permitindo o acesso da população ao planejamento total da gestão, viabilizando uma maior garantia de sua participação como cidadão; constituindo então um espaço aberto para o debate e a decisão político-participativa. É a partir da participação popular junto à administração pública que será possível estabelecer metas e prioridades de investimentos em obras e serviços a serem realizados no município, anualmente, a partir dos recursos orçamentários disponíveis.

O OP é um instrumento que possui caráter educativo, já que permite a participação da comunidade nos principais problemas do município, bem como conheça as limitações orçamentárias e os principais obstáculos burocráticos na realização de projetos. Ao atuar como agente efetivo no orçamento participativo, o cidadão deixa de ser um mero coadjuvante e assume papel de tomador de decisões sobre os recursos/investimentos públicos. A efetiva realização e implementação do orçamento participativo podem ser visualizadas como um fortalecimento da democracia na gestão municipal.

\section{Referências}

ABRUCIO, F. L.; COSTA, V. M. F. Reforma do Estado e contexto federativo brasileiro. São Paulo: Konrad-Adenauer-Stiftung, 1998.

AGRA, Walber de Moura Agra. Curso de Direito Constitucional. 6 ${ }^{\text {a }}$ Ed. Rio de janeiro: Editora Forense, 2010.

ARENDT, Hannah. A condição humana. 7ª ed. Rio de Janeiro: Forense Universitária, 1995. 
AVRITZER, L. O orçamento participativo e a teoria democrática: um balanço crítico. 2003. Disponível em $\quad<$ http://www.democraciaparticipativa.org/files/LeonardoAvritzerOor\%E7amentoparticipativoeateoriademocr\%R1ticaumbalan\%E7ocr\%EDtico.pdf $>$, acesso em novembro, 2013.

AVRITZER, L. Teoria democrática e deliberação pública. Lua Nova: Revista de cultura e política. São Paulo, n. 50, 2000. Disponível em <http://www.scielo.br/scielo.php?script=sci_arttext\&pid=S0102-

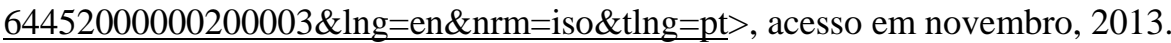

BAGGUley, P. Post-fordism and enterprise culture: flexibility, autonomy and changes in economic organization. In: KEAT, R.; ABERCROMBIE, N. (Eds.). Enterprise Culture. Routledge: London, 1991.

BALEEIRO, Aliomar. A Constituição de 1981. Brasília. Centro de Ensino a Distância. 1987.

BAQUERO, M. Democracia, cultura e comportamento político: uma análise da situação brasileira. In: PERISSINOTTO, R.M.; FUKS, M., (Orgs.). Democracia: teoria e prática. Rio de Janeiro: Relume-Dumará; Curitiba: Fundação Araucária, 2002.

BARRETO, M. I. As organizações sociais na reforma do Estado brasileiro. In: BRESSER-PEREIRA, L.C.; GRAU, N. C. G. (Orgs.). O público não-estatal na reforma do Estado. Rio de Janeiro: Editora FGV, 1999.

BRESSER-PEREIRA, L. C. Da administração pública burocrática à gerencial. Revista do Serviço Público, v. 120, n. 1, 1996.

BRESSER-PEREIRA, L. C. Reforma do Estado nos anos 90: lógica e mecanismos de controle. Brasília: MARE, Cadernos MARE, n. 1, 1997.

BRESSER-PEREIRA, L. C. Reforma do Estado para a cidadania: a reforma gerencial brasileira na perspectiva internacional. Brasília: ENAP/ Editora 34, 1998a.

BRESSER-PEREIRA, L. C. Gestão do setor público: estratégia e estrutura para um novo Estado. In: BRESSER-PEREIRA, L. C.; SPINK, P. (Orgs). Reforma do Estado e administração pública gerencial. Rio de Janeiro: Editora FGV, 1998b.

BITTAR, Eduardo C.B. Curso de Filosofia do Direito. $5^{\text {a }}$ ed. São Paulo: Editora Atlas, 2007.

BOBBIO, Norberto. A Era dos Direitos. 17 Tiragem. Rio de Janeiro: Editora Campus, 1992.

BOBBIO, Norberto. O futuro da democracia. São Paulo: Paz e Terra, 2000.

BONAVIDES, Paulo; Miranda Jorge; AGRA, Walber de Moura. Comentários à Constituição Federal de 1988. Rio de Janeiro: Editora Forense, 2009.

Brasil. Constituição da República Federativa do Brasil. 05 out. 1988. São Paulo: Revista dos Tribunais, 2002. 
BRASIL. Constituição Federal de 1988. São Paulo: LTr, 2008.

CANOTILHO, José Joaquim Gomes. Direito Constitucional. 6ª Ed. Coimbra: Liv. Almedina, 1993.

CARMO CARVALHO, M. Eppur si muove... Os movimentos sociais e a construção da democracia no Brasil. Campinas, 1997. 177 p. Dissertação (Mestrado em Ciência Política) - IFCH, UNICAMP.

CARBALHO, M.C.B.; Gestão social: alguns apontamentos para o debate. In: RICO, E.M.;

RAICHELIS, R. (Orgs.). Gestão social: uma questão em debate. São Paulo: IEE, 1999.

CARVALHO, A. B. As vicissitudes da reforma gerencial no Brasil: uma abordagem analítica. In: ENCONTRO NACIONAL DA ASSOCIAÇÃO NACIONAL DOS PROGRAMAS DE PÓSGRADUAÇÃO EM ADMINISTRAÇÃO, 23., 1999, Foz do Iguaçu. Anais. Foz do Iguaçu: ANPAD, 1999. COLLINS, D. Management Fads and Buzzwords: Critical-Practical Perspectives. London: Routledge, 2000.

CARVALHO, Kildare Gonçalves. Direito Constitucional- Teoria do Estado e da Constituição. Direito Constitucional Positiva- 12 ${ }^{\mathrm{a}}$ ed. Belo Horizonte: Del Rey, 2006.

COSTA, G.P. Cidadania e participação: impactos da política social num enfoque psicopolítico. Curitiba: Juruá Editora, 2009.

DAGNINO, E. Sociedade civil e espaços público no Brasil. In: DAGNINO, E. Sociedade civil e espaços públicos no Brasil. São Paulo: Paz e Terra, 2002, p. 9-15.

DALLARI, Dalmo de Abreu. Elementos de Teoria Geral do Estado. 16ª ed. São Paulo: Saraiva, 1999.

DIAS, M.R. Na encruzilhada da teoria democrática: efeitos do orçamento participativo sobre a Câmara Municipal de Porto Alegre. Tese de Doutoramento. Rio de Janeiro, Iuperj, 2000.

DINIZ, E. Crise, reforma do Estado e governabilidade. Brasil 1985- 95. Rio de Janeiro: Editora FGV, 1997. DINIZ, E. Globalização, reformas econômicas e elites empresariais. Rio de Janeiro: Editora FGV, 2000.

DOIMO, A. M. A vez e a voz do popular: movimentos sociais e participação política no Brasil pós-70. Rio de Janeiro: Relume-Dumará, ANPOCS, 1995.

DU GAY, P. Enterprise culture and ideology of excelence. New Formations, n. 13, p. 45-61, 1991. FAORO, R. Os donos do poder: formação do patronato político brasileiro. São Paulo: Globo, 1995 [1957]. v. 1 e 2 .

FERREIRA, A. L. S. Lages, um jeito de governar. Pólis, n. 5, 1991. 35 p.

GENRO, T. Teses para a criação de uma política democrática e socialista. In: GENRO, T. (Coord.). Porto da Cidadania: esquerda no governo de Porto Alegre. Porto Alegre: Artes e Oficíos, 1997. 
GENRO, T. O futuro por armar: democracia e socialismo na era globalitária. Petrópolis: Editora Vozes, 1999. GENRO, T. Co-gestão: reforma democrática do Estado. In: FISCHER, N. B.; MOLL, J. (Orgs.). Por uma nova esfera pública: a experiência do orçamento participativo. Petrópolis: Editora Vozes, 2000.

GIACOMINI, J. Orçamento público. São Paulo: Atlas, 1997.

GOHN, M. G. História dos movimentos e lutas sociais: a construção da cidadania pelos brasileiros. São Paulo: Loyola, 1995.

GONÇALVES, H.L. Uma visão crítica do orçamento participativo. Rio de Janeiro: Editora Lúmen Júris, 2005.

GREY, C. Towards a critique of managerialism: the contribution of Simone Weil. Journal of Management Studies, v. 33, n. 5, p. 591-612, 1996.

GRUPO DE ESTUDOS SOBRE A CONSTRUÇÃO DEMOCRÁTICA. Os movimentos sociais e a construção democrática: sociedade civil, esfera pública e gestão participativa. Revista Idéias, n. 5/6, p. 7$122,1999$.

GUERREIRO RAMOS, A. A nova ignorância e o futuro da administração pública na América Latina. Revista da Administração Pública, v. 4, n. 2, p. 7-45, 1970.

GUERREIRO RAMOS, A. A nova ciência das organizações: uma reconceituação da riqueza das nações. Rio de Janeiro: Editora da FGV, 1983.

GUSTIN, Miracy Barbosa de Souza. Cidadania e Inclusão Social. Belo Horizonte: Editora Fórum, 2008.

HARVEY, D. Condição pós-moderna. São Paulo: Edições Loyola, 1992 [1989]. 036-049 4826.01 .05 , 16:48 JAN./MAR. 2005 • ORAE • 49 ANA PAULA PAES DE PAULA HEELAS, P. Reforming the self: enterprise and the characters of thatcherism. In: KEAT, R.; ABERCROMBIE, N. (Eds). Enterprise Culture. Routledge: London, 1991.

JACOBI, P. Políticas sociais e ampliação da cidadania. Rio de Janeiro: Editora da FGV, 2000.

LOUREIRO, M. R.; ABRUCIO, F. L. Burocracia e política na nova ordem democrática no Brasil. In: ENCONTRO NACIONAL DA ASSOCIAÇÃO NACIONAL DOS PROGRAMAS DE PÓSGRADUAÇÃO EM ADMINISTRAÇÃO, 22., 1998, Foz do Iguaçu. Anais. Foz do Iguaçu: ANPAD, 1998.

LÜCHMANN, L.H.H. Possibilidades e limites da Democracia Deliberativa: a experiência do Orçamento Participativo de Porto Alegre. Campinas, 2002, tese (Doutorado em Ciências Sociais), Universidade de campinas.

MARE. Organizações sociais. Cadernos MARE, n. 2, 1997a. 75 p.

MARE. Programa de Qualidade e Participação na Gestão Pública. Cadernos MARE, n. 4, 1997b. 62 p. 
MARE. Agências executivas. Cadernos MARE, n. 9, 1998a. 55 p.

MARE. Programa de Reestruturação e Qualidade dos Ministérios. Cadernos MARE, n. 12, 1998b. 47 p.

MARE. Avanços da reforma na Administração Pública (1995-1998). Cadernos MARE, n. 15, 1998c. 129 p.

MARIA, C. Meritocracia à brasileira: a trajetória da carreira dos gestores governamentais. São Paulo, 2000. 145 p. Dissertação (Mestrado em Administração Pública e Governo) - EAESP, FGV.

MELO, Getúlio Costa. Evolução histórica do conceito de cidadania e a Declaração Universal dos Direitos do Homem. $\quad<\quad$ http://ambitojuridico.com.br/site/?n_link=revista_artigos_leitura\&artigo_id=13959 > ; fevereiro/2017.

MENDES, Gilmar Ferreira; COELHO, Inocêncio Mártires; BRANCO, PAULO Gustavo Gonet. Curso de Direito Constitucional. $2^{\mathrm{a}}$ ed. São Paulo: Saraiva, 2008.

MEZZOMO KEINERT, T. M. Administração Pública no Brasil: crises e mudanças de paradigmas. São Paulo: Annablume, Fapesp, 2000.

MONTEIRO, J. V. Economia e política: instituições de estabilização econômica no Brasil. Rio de Janeiro: Editora Fundação Getúlio Vargas, 1997.

MONTEIRO, J. V. As regras do jogo - o Plano Real: 1997-2000. Rio de Janeiro: Editora FGV, 2000.

MORAES, Alexandre. Constituição do Brasil Interpretada. São Paulo: Atlas. 2002.

MORRIS, P. Freeing the spirit of enterprise: the genesis and development of the concept of enterprise culture. In: KEAT, R.; ABERCROMBIE, N. (Eds.). Enterprise Culture. Routledge: London, 1991.

NOGUEIRA, M. A. As possibilidades da política: idéias para a reforma democrática do Estado. Rio de Janeiro: Paz e Terra, 1998.

OLIVEIRA, F. et al. Quanto melhor, melhor: o acordo das montadoras. Novos Estudos Cebrap, n. 36, p. 3-7, jul. 1993.

OLIVEIRA, F. A derrota da vitória: a contradição do absolutismo de FHC. Novos Estudos Cebrap, n. 50, p. 13-21, mar. 1998.

OLIVEIRA, Pérsio Santos de. Introdução á Sociologia. Série Brasil.25a Ed. São Paulo: editora Ática, 2006.

OSBORNE, D.; GAEBLER, T. Reinventando o governo. Brasília: MH Comunicação, 1994 [1992]. SCHWARTZMAN, S. Bases do autoritarismo brasileiro. Rio de Janeiro: Campus, 1982. 
PAULO, Vicente; ALEXANDRINO, Marcelo. Direito Constitucional Descomplicado. $6^{a}$ ed. São Paulo: Editora Método, 2010.

PEREIRA, Christiane Furtado Machado; silva, Eduardo Moraes Lameu; OLIVEIRA, Waidd Francis de. Orçamento Participativo. Revista Athenas. vol. 2, ano. III, ago.-dez. 2014 / ISSN 2316-1833

PIOVESAN, Flávia. Direitos Humanos e o Direito Constitucional Internacional. Max Limond. 2000.

PIRES, V. Orçamento participativo: o que é, para que serve, como se faz. São Paulo: Manole, 2001.

RODRIGUES, W.C. Metodologia científica. Paracambi: FATEC/IST, 2007.

SANCHES, Oswaldo. M. Dicionário de Orçamentos, Planejamentos e áreas afins. Brasília: Prisma, 1997. SILVA, José Afonso da. Curso de Direito Constitucional Positivo, São Paulo.

SANTOS JÚNIOR, O.A. Democracia e governo local. Rio de Janeiro: Revan/Fase, 2001.

SANTOS, B.S.; AVRITZER, L. Para ampliar o cânone democrático. In: SANTOS, B.S. (Org.). Democratizar a democracia: os caminhos da democracia participative. Rio de Janeiro: Civilização Brasileira, 2003.

SOUZA, C. Construção e consolidação de instituições democráticas: papel do orçamento participativo. São Paulo Perspec., 15(4):84-87, out./dez. 2001.

SOUZA SANTOS, B. A reinvenção solidária e participativa do Estado. In: BRESSER-PEREIRA, L. C.; WILHEIM, J.; SOLA, L. Sociedade e Estado em transformação. São Paulo: Unesp; Brasília: ENAP, 1999. SPINK, P. The rights approach to local public management: experiences from Brazil. Revista de Administração de Empresas, v. 40, n. 3, p. 45-65, 2000.

TENÓRIO, F. Gestão social: uma perspectiva conceitual. Revista de Administração Pública, v. 32, n. 5, p. 7-23, 1998. WAINWRIGHT, H. Uma resposta ao neoliberalismo: argumentos para uma nova esquerda. Rio de Janeiro: Zahar, 1998.

TEIXEIRA, Alberto. Guia da cidadania e transparência: prevenção contra corrupção. Fortaleza: Fundação Konrad Adenauer, 2016.

WILGES, I.J. Finanças públicas: orçamento e direito financeiro. Porto Alegre: Editora AGE, 2006.

\section{Como citar este artigo (Formato ABNT):}

SANTOS, Sony L.J.; VILAS BOAS, Jorge K.; OLIVEIRA, Mário L.; SILVA, Mayara L.; .; CAFFÉ FILHO, Hesler P. O Orçamento Participativo na Gestão Pública. Id on Line Revista Multidisciplinar e de Psicologia, Julho de 2017, vol.11, n.36, p.146-169. ISSN: 1981-1179.

Recebido: 20.06.2017

Aceito: 27.07.2017 